\title{
TUMORES OSEOS CONDROIDES: CONDROMAS VERSUS CONDROSARCOMAS CONVENCIONALES
}

\author{
Drs. Iván Melo $\mathbf{G}^{(1)}$, Virginia Martínez $C^{(2)}$.
}

1. Unidad de Radiología e Imágenes. Clínica Santa María.

2. Unidad de Anatomía Patológica Clínica Santa María.

\begin{abstract}
Chondroid lesions present some radiologic features which are common to benign chondroid lesions and chondrosarcomas of low-grade. It is not always possible to differentiate them, and a careful analysis must be looked. We revised the main characteristics of the continuum EnchondromaConventional Chondrosarcoma from the perspective of plain X-ray films, Computed Tomography and Magnetic Resonance imaging.
\end{abstract}

Key words: Bone Tumor, Chondrosarcoma, Enchondroma, Radiology.

Resumen: Las lesiones condroides presentan aspectos radiológicos que son comunes para las de carácter benigno y condrosarcomas convencionales de bajo grado. La diferenciación no siempre es posible y se debe considerar una cuidadosa evaluación imagenológica patológica y clínica. Se revisan las principales características imagenológicas del continuo encondroma-condrosarcoma convencional desde la perspectiva de la radiología simple, tomografía computada y resonancia magnética.

Palabras clave: Condrosarcoma, Encondroma, Tumor óseo, Radiología.

\section{Introducción}

Los tumores condroides primarios, excluyendo el osteocondroma, constituyen un desafío diagnóstico, dado que existe una continuidad tanto en el aspecto radiológico como histopatológico entre encondromas $(E C)$ y condrosarcomas de bajo grado (CBG). La diferenciación radiológica es particularmente difícil cuando se localizan en el esqueleto apendicular proximal; sin embargo una adecuada caracterización imagenológica y clínica, es importante para la evaluación anatomopatológica, la

Melo I. Tumores óseos condroides: Condromas versus condrosarcomas convencionales. Rev Chil Radiol 2005; 11: 170-178.

Correspondencia: Dr. Iván Melo G.

E-mail:melo.ivan@gmail.com cual en definitiva determinará el manejo clínico radicalmente diferente para ambas patologías.

En esta perspectiva se revisa la literatura y el material de archivo de 72 casos de la unidad de anatomía patológica de Clínica Santa María (CSM) de lesiones condroides; 64 benignas y 8 CBG. Estos casos provienen del equipo de tumores óseos del Instituto Traumatológico y de la Unidad de Traumatología de CSM. La disponibilidad en el archivo solo de las imágenes radiológicas más representativas, solo nos permite ilustrar y destacar las características principales de estas lesiones.

\section{Encondromas, condrosarcomas convencionales, y tumores condroides de conducta biológica} incierta.

De los tumores óseos primarios los condroides son los más frecuentes, superados sólo por los de estirpe hematopoyética, generalmente mielomas. En la cohorte de tumores óseos de Dahlin y Unni de la Clínica Mayo, corresponden al 21,8\%, sobre un total de $11.087 \operatorname{casos}^{(1)}$.

Los condromas corresponden al grupo de lesiones condroides benignas que reúnen encondromas medulares o centrales, condromas periostales, y encondromatosis en las cuales se incluyen la enfermedad de Ollier y el síndrome de Maffuci.

Encondromas. El EC es el tumor primario óseo benigno más frecuente, en el contexto de un hallazgo incidental, representando entre el $3-18 \%$ de las biopsias óseas. En la práctica clínica representan entre el 10 al $25 \%$ de los tumores óseos benignos ${ }^{(2,3)}$. En la serie de Dahlin y Unni, que incluye al osteocondroma, los condromas aparecen en tercer lugar entre los tumores óseos benignos (Gráfico I). En el Registro Nacional de Tumores Óseos (RENATO), corresponden al $15.5 \%$ de los tumores primarios.

En su localización habitual en manos generalmente en las falanges proximales de los 


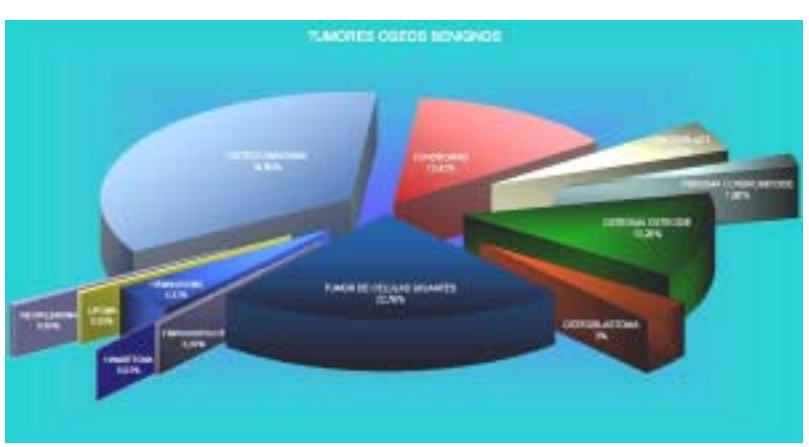

Gráfico I: Frecuencia de tumores óseos benignos (Referencia 1).

dedos, se presentan como lesiones clásicamente indoloras; cuando el dolor está presente es secundario a fracturas.

Los tumores condroides pueden presentar una matriz cartilaginosa no mineralizada o mineralizada, esta última propia de lesiones condroides clásicas.

EI EC es una lesión bien delimitada cuya matriz varía desde marcadamente osteolítica hasta intensamente mineralizada, observándose en estos casos calcificaciones puntiformes, en grumos, anillos o arcos. Pueden presentar conducta expansiva en los huesos cortos y planos observándose erosión endostal prominente. En cambio en huesos tubulares de mayor tamaño se acepta una mínima expansión y muy escasa erosión endostal ${ }^{(2,3,5)}$. Generalmente miden menos de $3 \mathrm{~cm}$ y los mayores a $5 \mathrm{~cm}$ son excepcionales. Se distribuyen principalmente en huesos tubulares, largos, distales y escasamente en huesos planos. Su ubicación clásica es la región metadiafisiaria, seguido de la diafisiaria; la localización en epífisis o adyacentes a la fisis es atípica (Tabla I).

Tienen arquitectura multinodular, con nódulos cartilagíneos rodeados de láminas de osificación condral lamelar, patrón típico de las lesiones de huesos tubulares grandes, en tanto que en huesos cortos son lesiones de patrón microscópico confluente. Aunque presenten erosión endostal, no

Tabla I. Distribución de encondromas en los principales sitios anatómicos afectados y en las distintas zonas de huesos tubulares largos (de referencia 2).

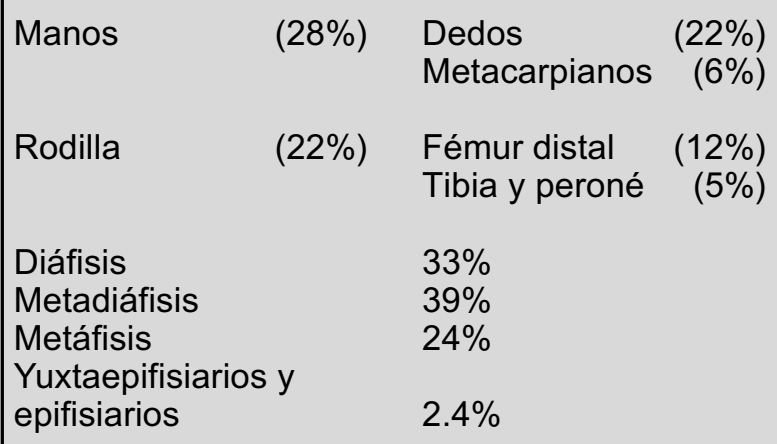

invaden los conductos de Havers. Son de baja actividad mitótica con escasa celularidad. En huesos pequeños son más celulares que en huesos largos, y la citología es más atípica ${ }^{(3,2,10)}$. Sin la correlación radiológica adecuada pueden ser confundidos con CBG.

Condrosarcoma: El Condrosarcoma es un tumor maligno con diferenciación condroide hialina que puede asociar cambios mixoides, y calcificación u osificación. Según la clasificación de tumores de la OMS, se dividen en primarios, secundarios y condrosarcomas especiales. Estos últimos se subdividen en desdiferenciado, de células claras, mesenquimal y periostal o yuxtacortical.

El Condrosarcoma Primario o Convencional corresponde al $90 \%$ de los casos, y se origina centralmente en un hueso sano ${ }^{(3)}$. Es un tumor frecuente, alcanzando al $27 \%$ en algunas series ${ }^{(4)}$. En la serie de Dahlin ${ }^{(1,2)}$, es la tercera frecuencia, con un $12.21 \%$, detrás del mieloma $(43.34 \%)$ y el osteosarcoma (20\%) (Gráfico II). En la casuística del RENATO, el condrosarcoma corresponde al $6.8 \%$ de los tumores primarios.

Es un tumor de la edad adulta, en mayores de 50 años, con su incidencia más alta entre la $5^{\underline{a}}$ y la $7^{\mathrm{a}}$ décadas.

El tipo central convencional es el más común. Su distribución clásica compromete huesos de la pelvis especialmente el iliaco y la región proximal del fémur en donde acumula el $65 \%$ casos. Otras ubicaciones son: costillas, húmero, fémur distal, sin embargo la ubicación proximal es la más común en el esqueleto apendicular (Figura 1). La localización en huesos pequeños de manos y pies es rara (1\%), y de excepción en esqueleto craneofacial (Tabla II).

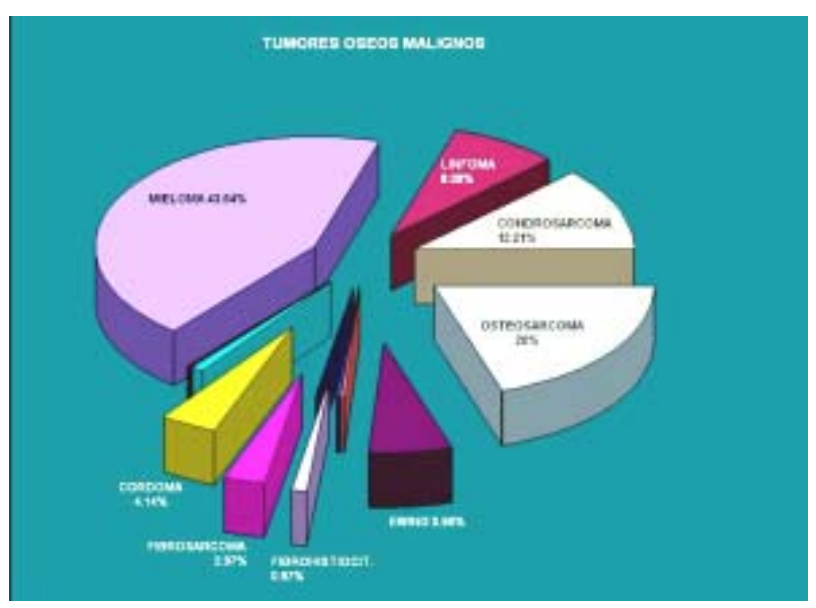

Gráfico II. Frecuencia de tumores óseos malignos. El condrosarcoma es la tercera frecuencia entre los tumores óseos primarios malignos. Las frecuencias menores corresponden a: Sarcoma de células gigantes, adamantinoma, Fibroma desmoplástico, hemangioendotelioma, hemangiopericitoma y liposarcoma (Referencia 1). 


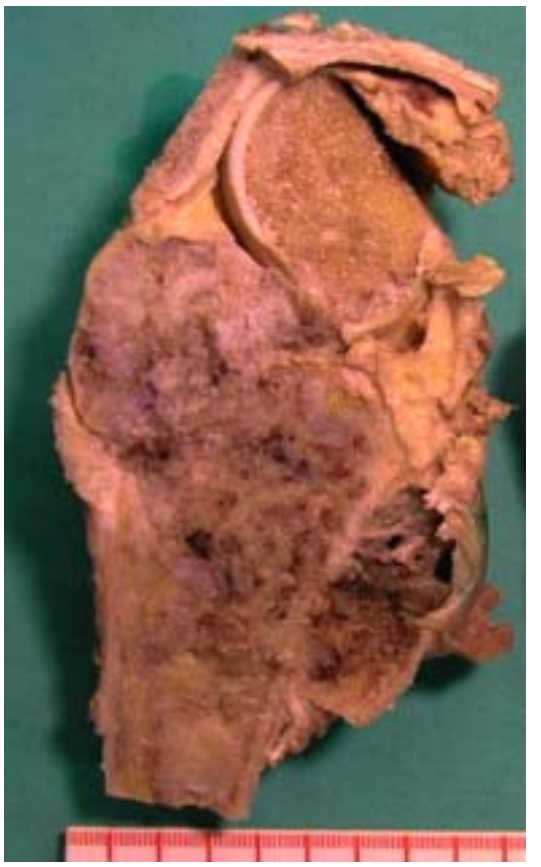

Figura 1. Pieza anatómica de condrosarcoma de fémur proximal.

Tabla II. Distribución de condrosarcomas en los principales sitios anatómicos afectados y en las distintas zonas de huesos tubulares largos (de referencia 4).

\begin{tabular}{llr} 
Esqueleto axial & $\begin{array}{l}\text { Acetábulo } \\
\text { Costillas }\end{array}$ & $(25 \%)$ \\
& $\begin{array}{l}\text { Vertebras } \\
\text { Escápula }\end{array}$ & $(7 \%)$ \\
& Esternón & $(5 \%)$ \\
& & \\
Esqueleto apendicular & Fémur & $(20-45 \%)$ \\
& Húmero & $(10-20 \%)$ \\
& Tibia & $(5 \%)$ \\
Metáfisis & & \\
Diáfisis & & $49 \%$ \\
Epífisis & & $36 \%$ \\
\hline
\end{tabular}

Clínicamente se caracterizan por dolor insidioso, progresivo y de larga duración. Masa y aumento de volumen se presentan en al menos un tercio de los casos, reportándose entre un $28 \%$ a $82 \%$ en distintas series. Fractura es la tercera forma de presentación como síntoma inicial, fluctuando entre $3 \%$ y $17 \%$ de los casos ${ }^{(2)}$.

La distribución en huesos largos predomina en la región metadiafisiaria, donde producen expansión fusiforme, con erosión endostal permeación, incluso engrosamiento cortical. Pese a la invasión extracompartimental existe escasa reacción periférica a nivel periostal. Presentan áreas de aspecto radiolúcido con la matriz mineral clásica en $60 \%-78 \%$ de lesiones ${ }^{(6,5)}$.

Encondromas versus Condrosarcomas: La evaluación radiológica es importante en el diagnóstico de la estirpe tumoral dado que los condroides exhiben la característica matriz mineral cartilagínea. La permeación cortical y la invasión del hueso medular, permiten separar malignos de benignos.

Histológicamente en algunos EC, nódulos cartilagíneos pueden observarse alejados del cuerpo tumoral principal; en los condrosarcomas, el tumor llena la cavidad medular y engloba médula normal en islotes de trabéculas, además de traspasar la cortical, son tumores hipercelulares y con atipia moderada, que varía ampliamente entre distintos campos de la muestra, lo que hace difícil diferenciarlos del EC.

Los criterios histológicos para la evaluación de CBG en huesos pequeños son diferentes, puesto que la hipercelularidad, atipia y cambios mixoides también se aprecian normalmente en el EC. En tanto, la conducta a permeación cortical y agresividad del hueso trabecular cobra mayor importancia ${ }^{(2,3,5,9)}$.

Existe una virtual continuidad histopatológica en el eje EC-CBG, las lesiones benignas pueden presentar áreas hipercelulares con escasas atipias, en tanto un CBG puede tener grandes áreas de apariencia benigna $^{(7)}$. La diferenciación basada en criterios de consenso, no siempre permiten la certeza de benignidad o malignidad, abriendo una categoría intermedia llamada tumores condroides de conducta biológica incierta (Figura 2). La diferenciación en éstas lesiones limítrofes estará basada en la evaluación imagenológica.

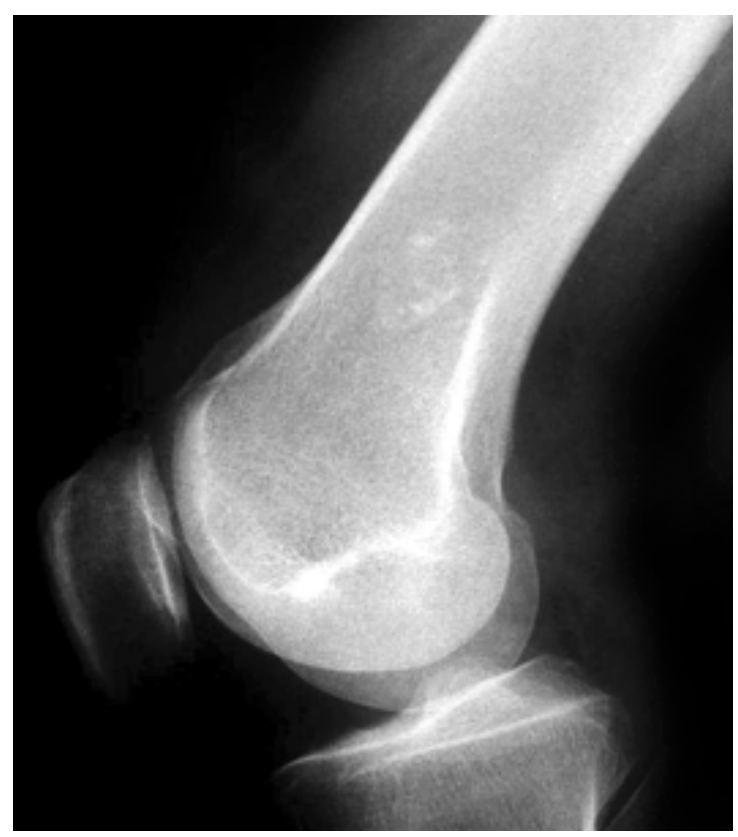

Figura 2. Tumor condroide de conducta incierta en fémur distal: La radiología es concordante con Encondroma central, diafisiario distal; sin embargo la biopsia por punción demostró una lesión condroide con áreas de proliferación moderadamente hipercelular y discretamente atipica. Estas lesiones deben mantenerse bajo control. 


\section{Evaluación por imágenes}

El rol de las imágenes es caracterizar la topografía y conducta biológica de la lesión, de acuerdo al esquema de compartimentos de Enneking, en la cual una cápsula es formada por tejidos comprimidos y compactados por el crecimiento tumoral. Alrededor de ésta hay una zona reactiva, en donde pueden existir células neoplásicas en forma de invasión extracapsular. La lesión, la cápsula y la zona reactiva se hallan en el interior de un compartimiento, delimitado por barreras naturales tales como la cortical ósea, septum intermuscular, cartílago articular, etc. Si el tumor las supera, se presenta la invasión extracompartimental ${ }^{(8,9)}$.

Radiología convencional: Las lesiones condroides son bien identificadas por ésta ya que presentan una matriz mineralizada clásica (Figura 3). La radiología convencional caracteriza bien EC pequeños de ubicación distal en el esqueleto apendicular, como islotes condroides, parcialmente calcificados, rodeados de hueso lamelar, constituyendo lesiones osteolíticas, geográficas, con escasa erosión endostal, de ubicación central que ocasionalmente se fracturan (Figuras 4,5).

Sin embargo una lesión de estirpe condroide puede presentar una morfología muy variable en cuanto a su agresividad tales como: Aspecto geográfico con bordes escleróticos o definidos no escleróticos (Figura 6), aspecto geográfico con bordes mal definidos (Figura 7), aparición de focos de erosión moteada (Figura 8 a,b), y finalmente lesiones permeativas con zonas de transición amplias (Figura $8 \mathrm{c}, \mathrm{d}$ ).

La combinación de los patrones de destrucción ósea y borde o transición de la lesión, nos permite estimar la velocidad de crecimiento lesional. Sin embargo, la radiología convencional de tumores óseos en este aspecto tiene baja eficacia diagnóstica $(54 \%)$, especialmente en estos tumores de baja actividad biológica $^{(7,10)}$ (Figura 9). Otra limitante es la gran variación interobservador, que se expresa al definir permeación cortical o definición de márgenes, variabilidad que aumenta frente a signos poco frecuentes, como la invasión extracapsular intracompartimental.

Las lesiones que se caracterizan como Condrosarcomas típicos reúnen márgenes mal definidos, erosión endostal de más de $2 / 3$ del espesor cortical aspecto visible huesos largos, permeación cortical, contornos lobulados, y matriz calcificada característica (Figuras 10,11, Tabla III). Estos hallazgos se observan en un $75 \%$ de los casos.

Tomografía Computada: La Tomografía multidetector constituye un valioso aporte al mejorar notablemente la sensibilidad y especificidad del diagnóstico sobre la base de los criterios de erosión/ permeación cortical, esclerosis/osteolisis de matriz mineral, reacción perióstica y la definición topográfica (Figura 12, Tabla IV).

Resonancia Magnética: La Resonancia Magnética (RM) incorpora la evaluación de la matriz no mineralizada, la alteración de la médula ósea (MO), el edema peritumoral, y la evaluación dinámica del patrón de realce con contraste paramagnético (Figura 13, Tabla V).

Es el mejor método para evaluar el compromiso de la $\mathrm{MO}$ y su reemplazo al permitir identificar los islotes de médula amarilla normal, hallazgo que expresa la conducta biológica del tumor, dado que una conducta agresiva oblitera, ocupa e infiltra la señal normal de ésta. Del total de EC, el $65 \%$ presentan islotes respetados de $\mathrm{MO}$, para el Condrosarcoma este hallazgo, en algunas series, se observa hasta en un 35\% de los casos, lo que se sugiere puede estar explicado por un CBG que se origina en un ECD previo.

Se ha propuesto el uso del estudio dinámico de captación de Gadolinio (ED-Gd) o Fast-Contrast enhanced MRI. Inicialmente las imágenes de RM con uso de contraste se obtenían en fase de equilibrio, dada la limitada resolución temporal disponible, observándose realce en forma de patrones septales y nodulares tanto en EC y CBG. Actualmente la disponibilidad de una mejor resolución temporal, permite el estudio de las curvas de realce para evaluar el comportamiento tumoral respecto a la vascularización en los primeros 10 segundos post-inyección. La heterogeneidad tumoral es sin embargo una causa conocida de error al realizar muestreos parciales, adquiriendo sólo una fracción o volumen parcial del tumor. Considerando esta limitante, el estudio ED-Gd permite identificar regiones sospechosas en lesiones conocidas y por tanto dirigir la biopsia.

EI ED-Gd caracteriza cuatro patrones de curvas de realce: (1) Realce arterial precoz, que declina rápidamente; (2) Ascenso exponencial un poco más tardío, seguido de una meseta o una fase de lento ascenso; (3) Realce lento y constante después de la curva arterial; (4) Falta o mínimo realce (Gráfico 3).

Folkman plantea que el realce precoz y exponencial en los condrosarcomas es probablemente resultado de neovascularización, que lleva a la lesión tumoral desde un metabolismo dependiente predominantemente de difusión, a uno dependiente predominantemente de perfusión. La difusión que es común para tumores malignos y benignos se ve en las fases tardías del realce, ella también explica por qué los septos de los Condrosarcomas se visualizan gruesos en comparación con los septos fibrovasculares más finos que se aprecian en su histología. La difusión sería mayor por una alta permeabilidad, y por inicio en fase temprana desde la 
neovascularización tumoral. En adultos una curva de realce precoz antes de los 10 segundos y exponencial es un predictor positivo de condrosarcoma (Especificidad 95\% y VPP 92\%), en tanto que la ausencia de realce precoz y tardío se correlaciona negativamente con malignidad (Sensibilidad y VPN 100\%) $^{(6,10,4)}$ (Figura 14).

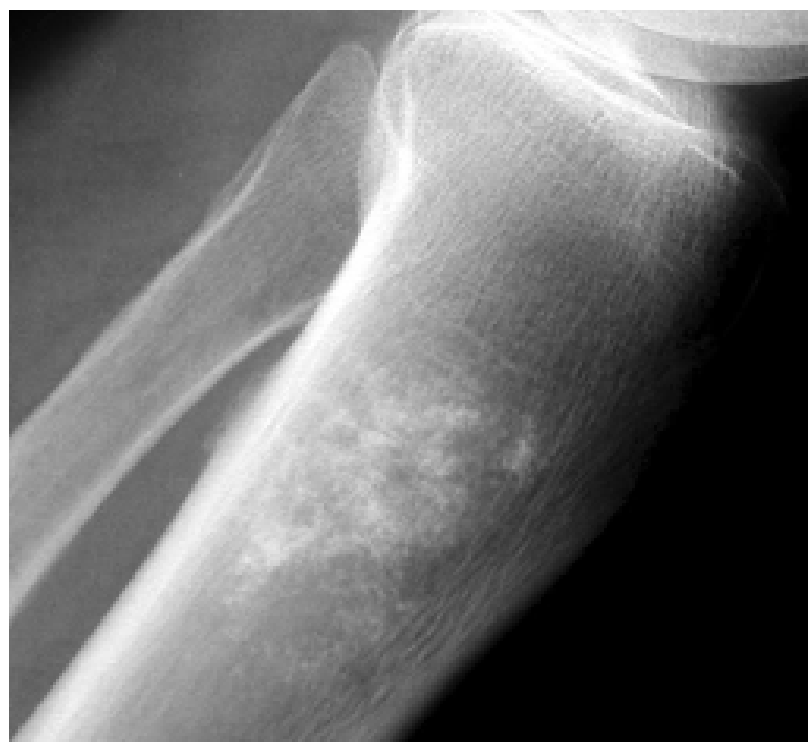

Figura 4. Rx de rodilla proyección lateral. Encondroma solitario central.

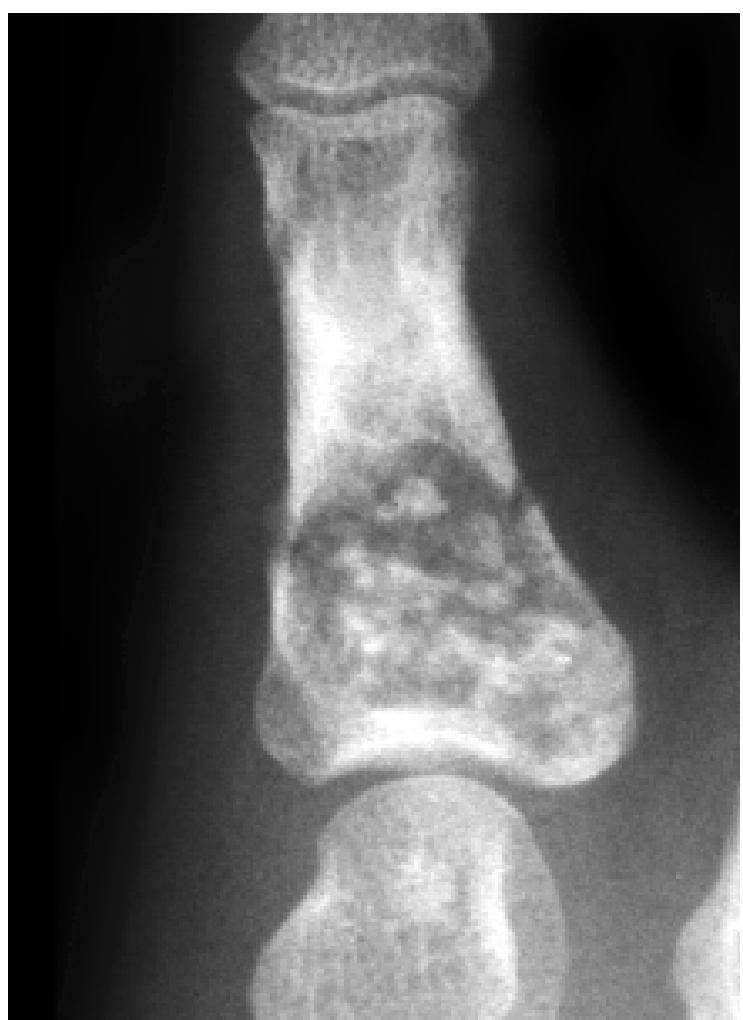

Figura 5. Encondroma fracturado, matriz condroide típica: Las densidades son de 1 a $5 \mathrm{~mm}$ de diámetro, en forma de lóbulos cartilaginosos. Algunos tumores de origen condral pueden desarrollar una maduración cartilaginosa completa, produciéndose formación ósea encondral.

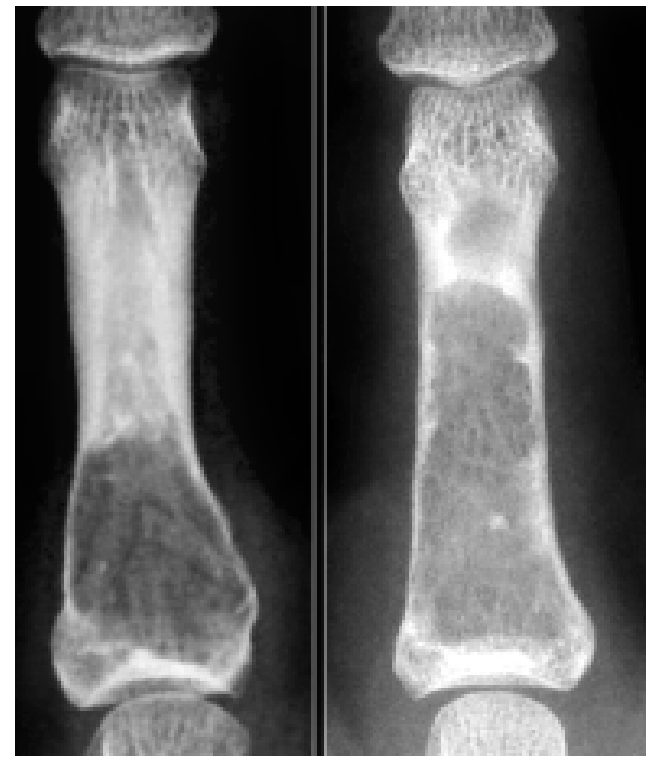

Figura 3 a,b. Rx de dedos. Encondromas de la primera falange con matriz mineralizada punteada. Obsérvense pequeños puntos aislados de densidad aumentada en el espesor de la lesión.

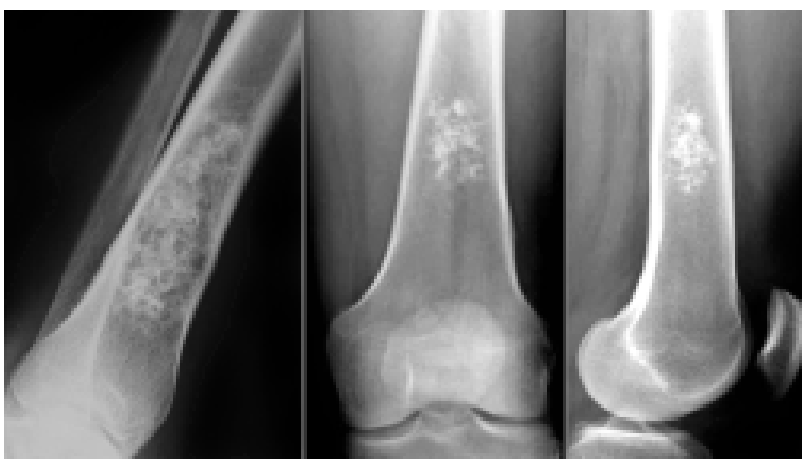

Figura 6 a-c. Encondromas centrales diafisiarios. a) Tibia distal se observa aspecto clásico, con bordes escleróticos, sin erosión endostal. b, c) Fémur distal en donde se observa lesión de matriz condroide, geográfica, sin borde esclerótico, y con erosión endostal no agresiva.

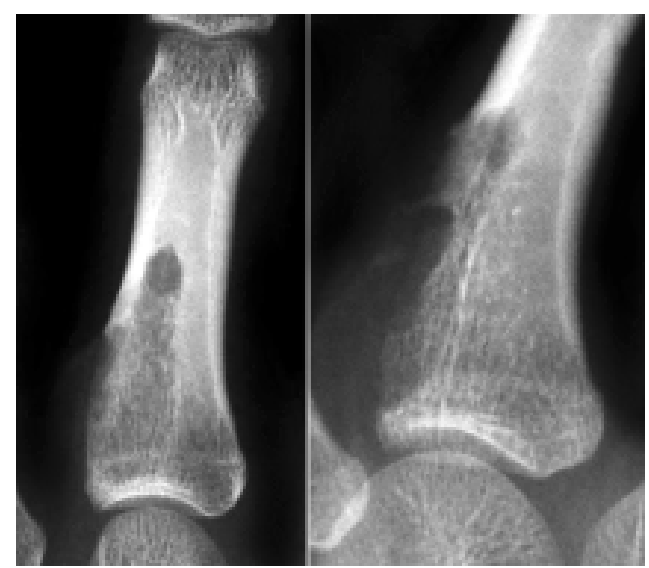

Figura 7 a,b. a) Encondroma de primera falange. Destaca su permeación cortical y extensión extracompartimental. En la histopatología se demostró marcada hipercelularidad y moderada atipia, sin embargo se consideró benigno. b) Detalle de la lesión en proyección oblicua. 


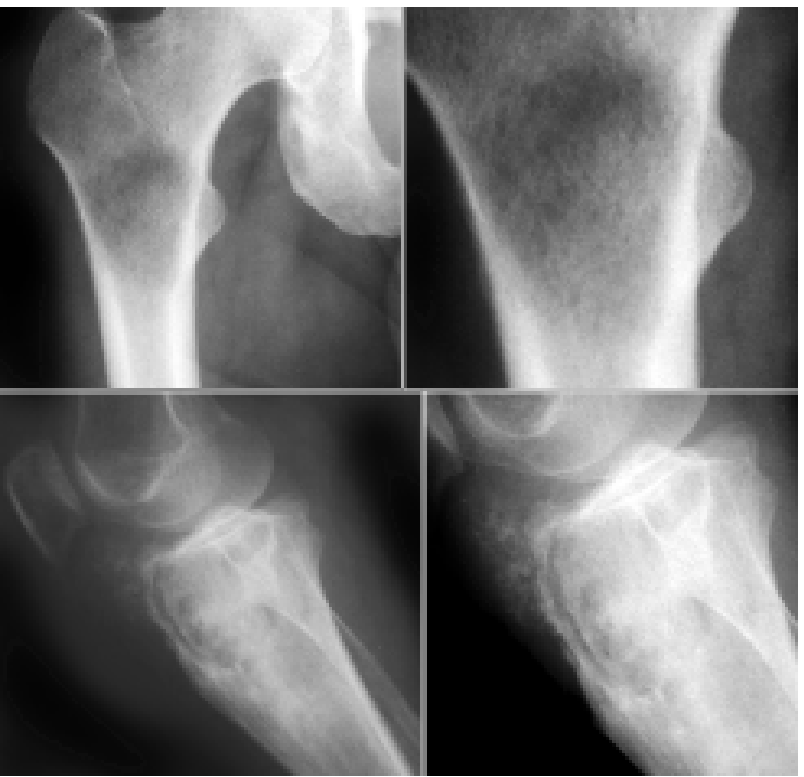

Figura 8 a-b. a,b) Condrosarcoma convencional $\mathbf{G}$ l, lesión geográfica, con zona de transición sin borde esclerótico. Proliferación de matriz osteoide atípica, que se extiende en los espacios medulares rodeando parte de la lesión condroide. Se planteo una zona de desdiferenciación tipo osteosarcoma en un condrosarcoma de bajo grado. c,d) Condrosarcoma convencional $G$ // de tibia: muestra una lesión mixta, agresiva, con zona de transición amplia y sin borde esclerótico, y con erosión endostal no agresiva.

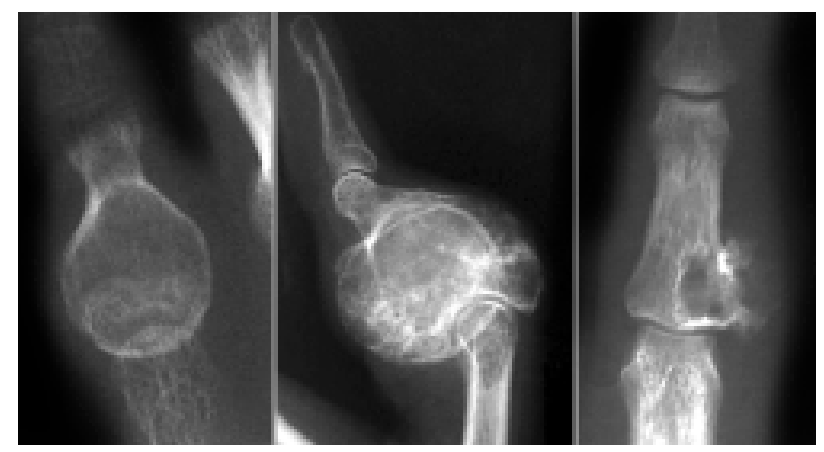

Figura 9 a-c. Encondromas atípicos: a) Encondroma de primera falange de ortejo: aspecto expansivo, insuflante, no habitual. b) Encondroma de falange; su aspecto expansivo está dado por una fractura antigua con remodelación. c) Aspecto poco habitual con permeación cortical y extensión extracompartimental.

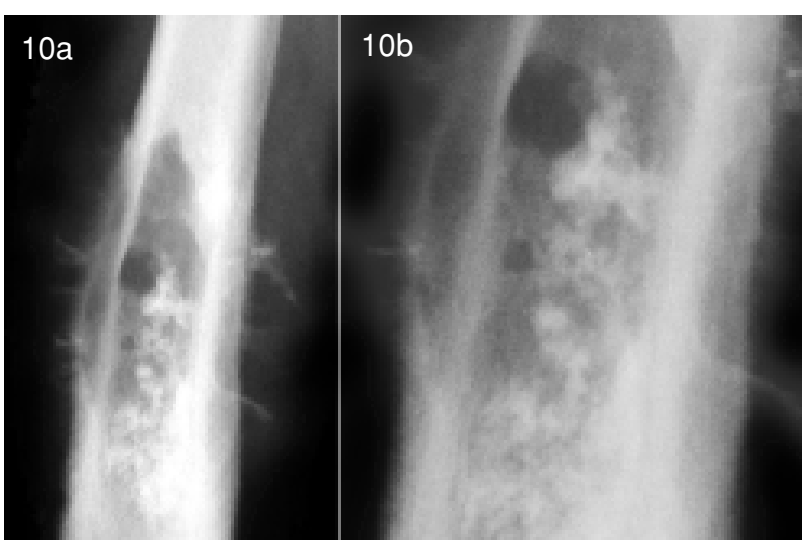

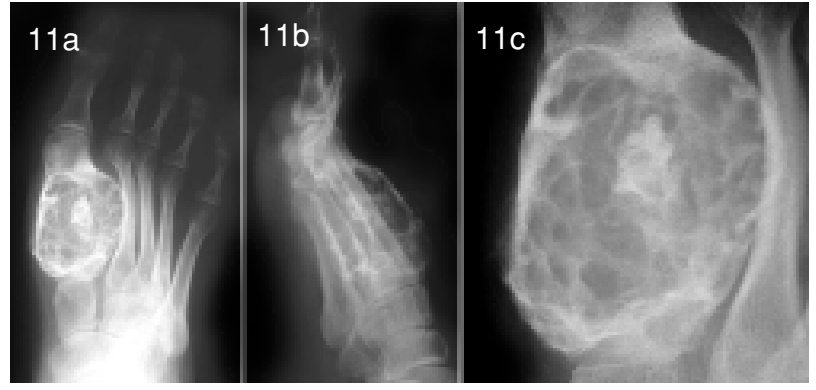

Figura 11 a-c. Condrosarcoma convencional G // de metatarsiano. a,b) $R x$ frontal y lateral mostrando aspecto insuflante, aparentemente sin importante permeación cortical. La resección demostró importante invasión de partes blandas, permeación cortical multifocal, con extenso compromiso de la articulación tarso-metatarsiana. c) Detalle demostrando lesión insuflante, con erosión endostal extensa, matriz mineralizada, extensión extracapsular y extracompartimental con reacción perióstica.

Tabla III: Sensiblidad de la radiología simple en el diagnóstico de Condrosarcoma convencional, de acuerdo a signos de agresividad, según referencias 4 y 6 (ND: no diagnóstica).

Condrosarcoma convencional: Sensibilidad diagnóstica de los signos principales en

Radiología simple.

1. Lesión central de aspecto lobulado con erosión endostal y penetración cortical

2. Erosión endostal $>2 / 3$ del espesor cortical

3. Erosión endostal > 2/3 del largo de la lesión

4. Componente de Partes Blandas $57 \%$ $75 \%$ ND $46 \%$

Figura 10 a,b. Condrosarcoma convencional de fémur $G$ II. a) Lesión mixta con áreas de matriz mineralizada combinadas con otras de condroide no mineralizado. Destaca la erosión cortical y trabecular, con extensa reacción perióstica. b) Detalle de la matriz mineralizada, su presencia y morfología no orienta sobre la conducta de la lesión. 

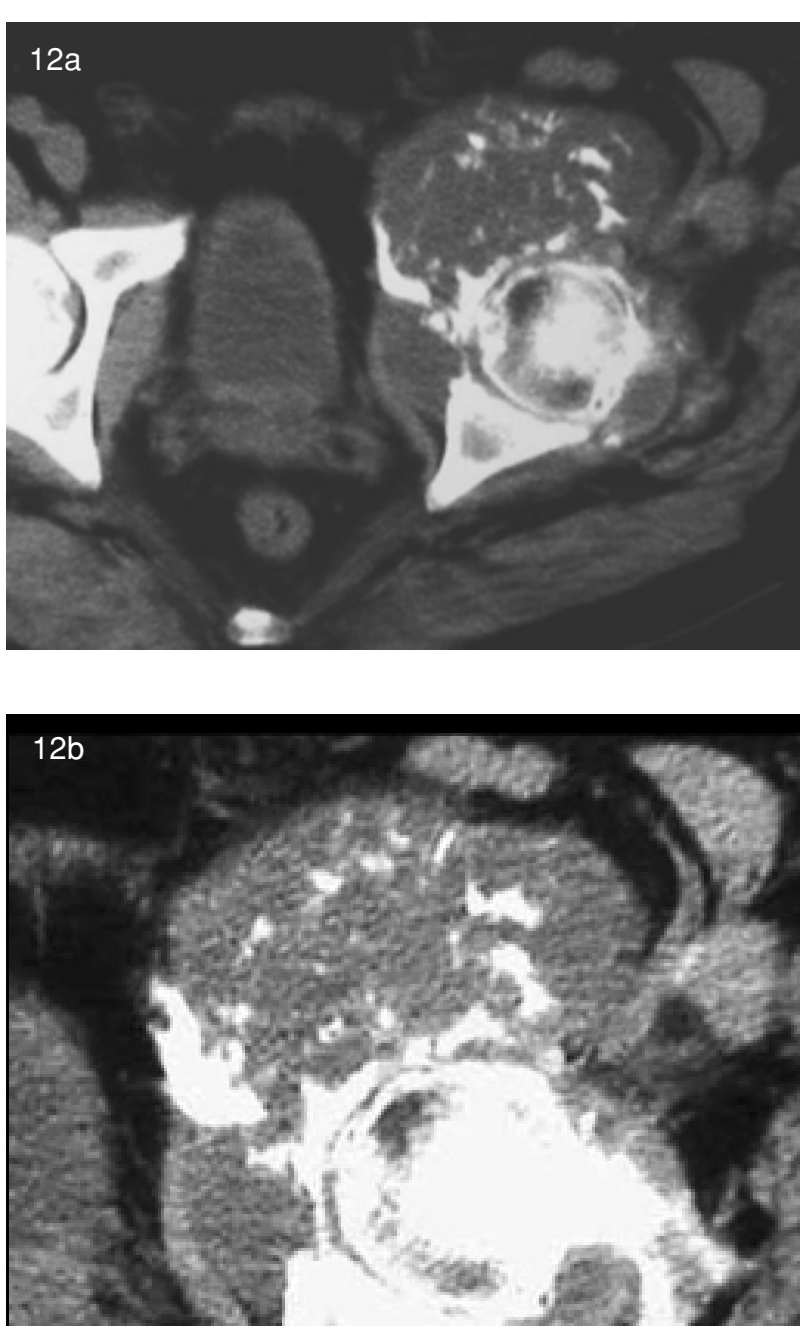

Figura 12 a,b. TC de pelvis. a) Condrosarcoma convencional de acetábulo, probablemente secundario, asociado a Condromatosis sinovial de 20 años de evolución. b) Detalle de la matriz mineralizada.

Tabla IV. Sensibilidad diagnóstica de la TC en el Condrosarcoma convencional, según referencia 4.

Condrosarcoma convencional: Sensibilidad de los signos principales en Tomografía Computada.

1. Erosión endostal focal mayor a $2 / 3 \quad 90 \%$ del espesor cortical

2. Erosión endostal longitudinal a lo $\quad 79 \%$ largo de la lesión

3. Erosión endostal con penetración $\quad 88 \%$ transcortical

4. Compromiso de partes blandas $\quad 59 \%$ extraóseas
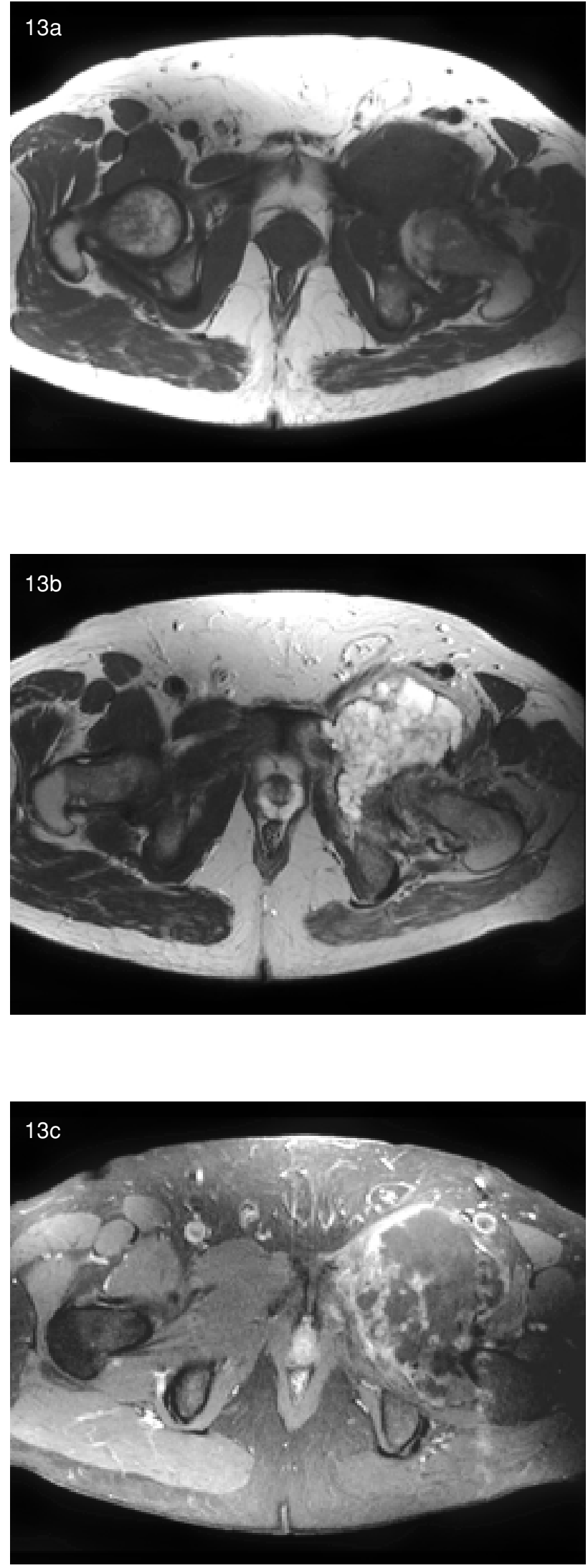

Figura 13 a-c. RM de pelvis. Condrosarcoma Acetabular. a) Secuencia T1 axial. b) Secuencia T2 axial. c) Secuencia T1 FS con Gd: Captación septada tardía en el área de sospecha. 
Tabla V. Sensibilidad de la Resonancia magnética en el diagnóstico de Condrosarcoma convencional, según referencia 4 (ND: no diagnóstica).

Condrosarcoma convencional: Sensibilidad de los signos principales en resonancia magnética.

1. Ausencia de Islotes de MO

$65 \%$ englobados en la lesión

2. Erosión endostal mayor $2 / 3$ espesor cortical

3. Penetración cortical

4. Arquitectura lobular septada

5. Edema peritumoral

6. Reacción perióstica

7. Reemplazo de MO en T1

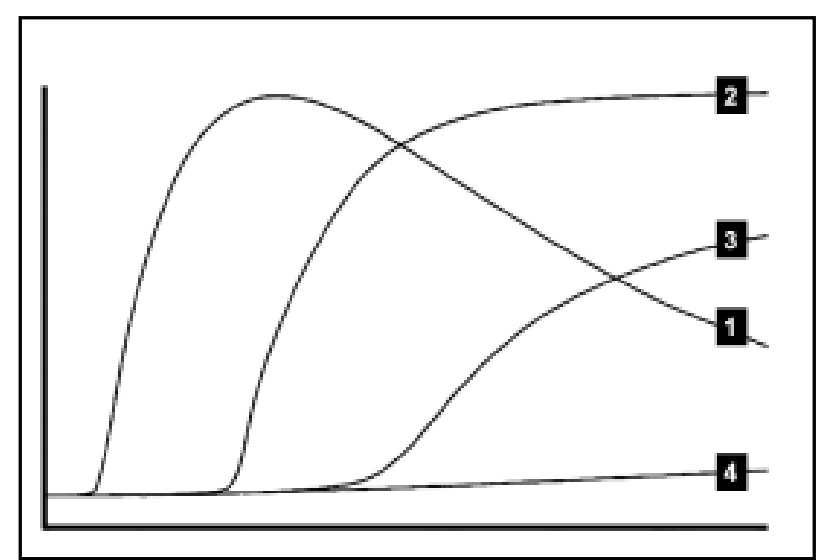

Gráfico III: Curvas de realce dinámico con Gadolinio.

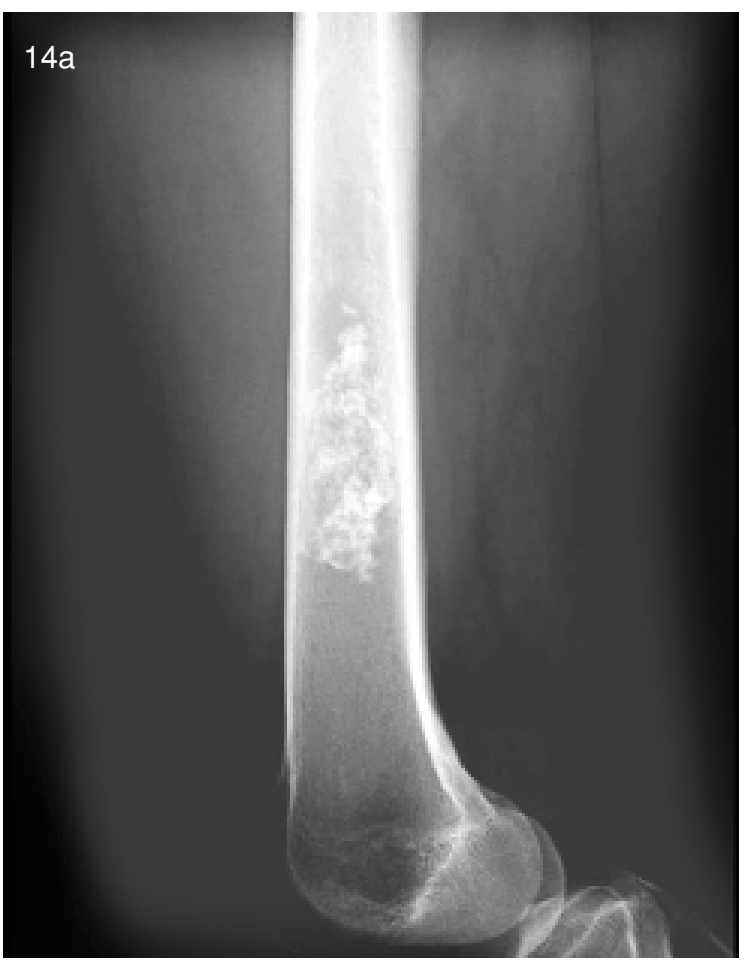

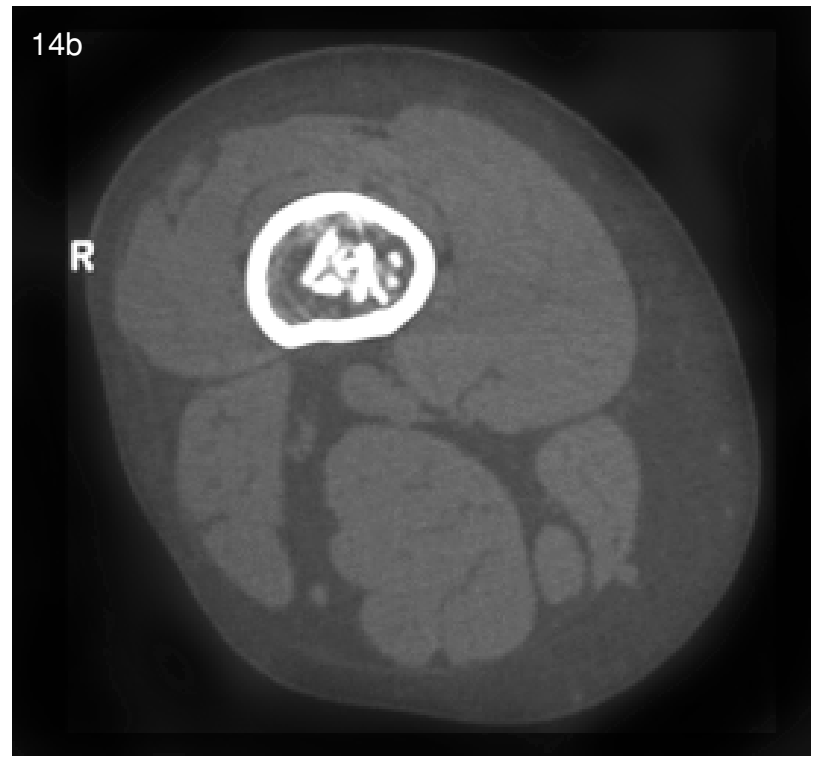

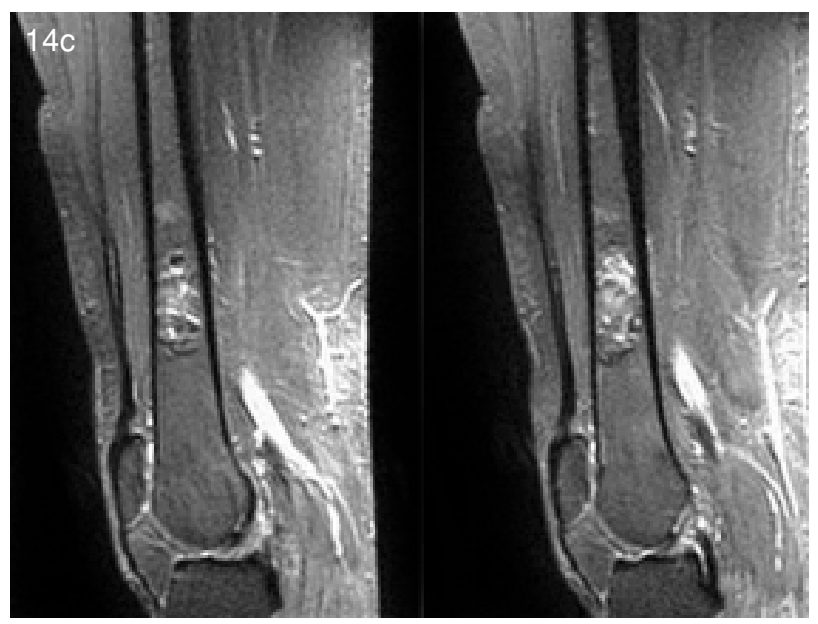

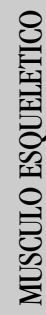

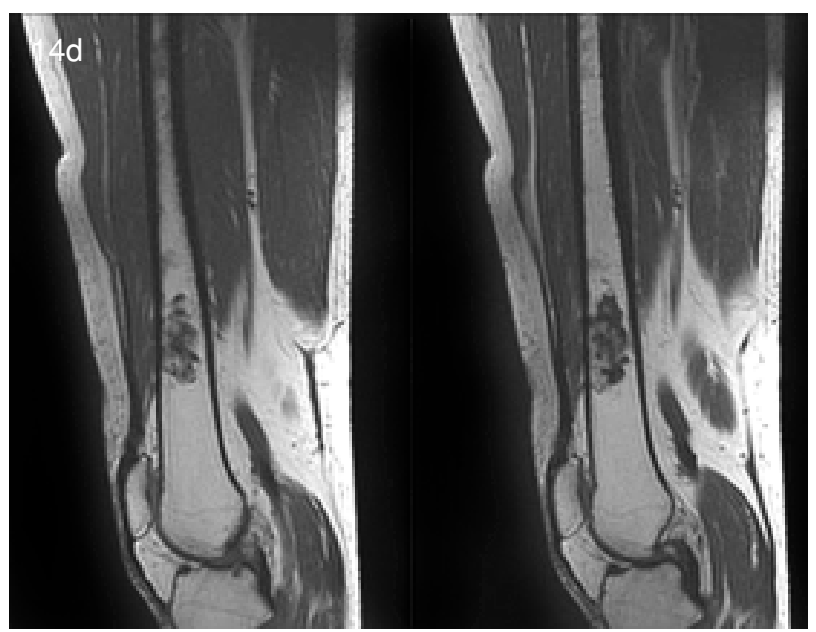




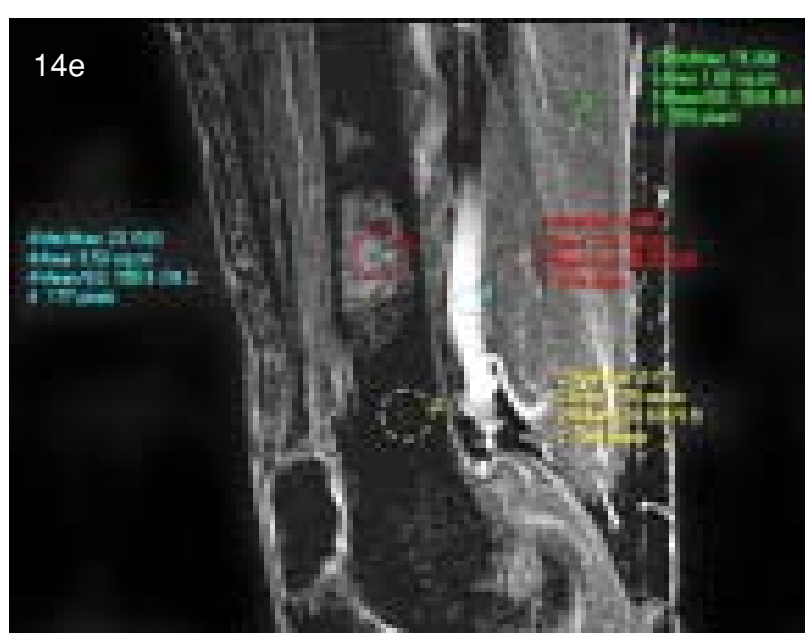

Figura 14 a-e. a) $R x$ simple hallazgo de lesión condroide femoral. b) TC. c) RM STIR sagital d) RNM T1 sagital. e) RM dinámica: Cuatro muestras asignadas a la lesión metadiafisiaria (1, rojo), la médula ósea metafisiaria (2, amarillo), músculo (3, verde), y arteria femoral (4, celeste).

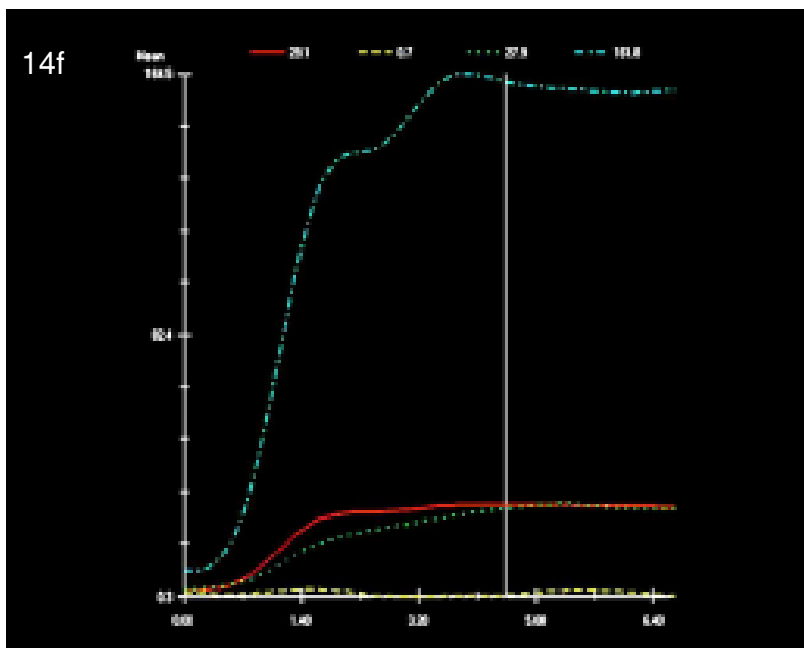

Figura 14 f. La curva de realce en la lesión (1, rojo) corresponde a un patrón tipo 4, lo que apoya una lesión benigna.

\section{Conclusión}

El estudio por imágenes de los tumores condroides revisados, orienta respecto a su conducta biológica y agresividad, además caracteriza la topografía tumoral y su extensión, elementos imprescindibles para la evaluación anatomopatológica y elaboración del pronóstico.
La extensión es el elemento de mayor importancia para determinar pronóstico, por lo cual el papel de la radiología y especialmente de la resonancia magnética presentan una gran utilidad.

\section{Agradecimientos}

Al equipo de Tumores Oseos del Instituto Traumatológico de Santiago por habernos permitido la revisión de su material, en especial al jefe de equipo, Dr. Orlando Webar C. y a los Drs. Alexander Mac Cawley, y Francisco J. Medina por su participación en la revisión y elaboración del texto.

\section{Bibliografía}

1. Unni K, Krishnan. Dahlin's Bone Tumors. General aspects and data on 11.087 cases. Fifth edition 1996. Lippincott-Raven: Philadelphia.1996; 25- 45, 71-108.

2. Giudici MA, Moser RP Jr, Kransdorf MJ. Cartilaginous Bone Tumors. Radiol Clin North Am. 1993; 31: 237-59. Review.

3. Fletcher CDM, Unni KK, Mertens F. (Eds.): World Heath Organization Classification of Tumors. Pathology and Genetics of Tumors of Soft Tissue and Bone. IARC PRESS: Lyon 2002. Pages 237-242, 247251.

4. Murphey MD, Walker EA, Wilson AJ et al. From The Archives of the AFIP: Imaging of Primary Chondrosarcoma: Radiologic-Pathologic Correlation. Radiographics. 2003; 23:1245-78. Review.

5. Murphey MD, Flemming DJ, Boyea SR, et al. From the Archives of the AFIP: Enchondroma versus Chondrosarcoma in the Appendicular Skeleton: Differentiating Features. Radiographics. 1998; 18: 1213-37.

6. Geirnaerdt, MJ, Hermans, J, Bloem, JL et al. Usefulness of Radiography in Differentiating Enchondroma from Central Grade 1 Chondrosarcoma. Am. J. Roentgenol AJR 1997; 169: 1097-1104.

7. Kendell SD, Collins MS, Adkins MC, et al. Radiographic differentiation of Ench ondroma from low-grade Chondrosarcoma in the Fibula. Skeletal Radiol. 2004; 33: 458-466.

8. P O'Donnell. Evaluation of focal bone lesions: basic principles and clinical scenarios. Imaging, 15, 2003; 298-323 E 2003. The British Institute of Radiology.

9. Letson D, Falcone R, Muro-Cacho CA. Pathologic and Radiologic Features of Primary Bone Tumors. Cancer Control. 1999; 6: 283-293.

10. Geirnaerdt MJ, Hogendoorn PC, Bloem JL et al. Cartilaginous Tumors: Fast Contrast-Enhanced MR Imaging. Radiology 2000; 214: 539-546. 